\title{
Malignant pleural mesothelioma
}

\section{To the editors:}

With great interest we have read the article on malignant pleural mesothelioma by Boutin et al. [1]. It was an excellent overview of many aspects of this disease. However we would like to comment on the following issues.

Although the staging procedure as advised by the International Mesothelioma Interest Group appears to be a step forward, we feel that it remains difficult to stage patients properly and select them for aggressive surgical approaches. Despite the use of computed tomography, magnetic resonance imaging and mediastinoscopy, a significant number of patients cannot be staged properly. Growth of the tumour in mediastinal structures as well as in tissue surrounding the diaphragmal sinus is often first recognized during surgery.

Mediastinal lymph node involvement is generally thought to be an uncommon and late manifestation in the course of the disease. During the last 3 yrs, we have performed mediastinoscopies on all patients considered candidates for surgical-based combination therapies. About one-third of the patients appeared to have mediastinal lymph node metastases. These findings suggest that lymph node metastasis is not occuring as late as is generally thought in this disease. In our opinion, surgical biopsies of mediastinal lymph nodes are an essential part of the staging procedure, especially when surgical therapy is considered.

In an attempt to improve the disappointing results of single modality treatments, several centres have initiated combination therapies. In general, these combinations are based on surgery and the primary goal is to improve local control. One of these combinations, not mentioned by the authors, is surgery and photodynamic therapy (PDT) [2-5]. PDT could well offer a valuable adjunct to surgery alone and might result in prolonged local tumour control. Currently several phase I and II studies are ongoing in the Netherlands and the USA.

H. Schouwink, P. Baas, E.T.H. Rutgers, F.A.N. Zoetmulder

Depts of Thoracic and Surgical Oncology, Netherlands Cancer Institute, Amsterdam, the Netherlands. Fax: 31 205122573

\section{References}

1. Boutin C, Schlesser M, Freanay $\mathrm{C}$, et al. Malignant pleural mesothelioma. Eur Respir J 1998; 12: 972-981.

2. Pass HI, Temeck BK, Kranda KZ, et al. Phase III randomized trial of surgery with or without intraoperative photodynamic therapy and postoperative immunochemotherapy for malignant pleural mesothelioma. Ann Surg Oncol 1997; 4: 628-633.

3. Takita H, Mang TS, Loewn GM, et al. Operation and intracavitary photodynamic therapy for malignant pleural mesothelioma: a phase 2 study. Ann Thorac Surg 1994; 58: 995-998.

4. Ris HB, Altermatt HJ, Nachbur B, et al. Intraoperative photodynamic therapy with $\mathrm{m}$-tetrahydroxyphenylchlorin for chest malignancies. Lasers Surg Med 1996; 18: 39 45.

5. Baas P, Murrer L, Zoetmulder FAN, et al. Photodynamic therapy as adjuvant therapy in surgically treated pleural malignancies. Br J Cancer 1997; 76: 819-826. 